\title{
DESCOLONIZAÇÃO E ACESSO À JUSTIÇA: PERSPECTIVAS PARA UMA PRÁXIS EMANCIPATÓRIA
}

\author{
Osvaldo Estrela Viegaz ${ }^{1}$ \\ Arari Vinicius Guimarães ${ }^{2}$
}

Resumo: o processo de descolonização é de extrema importância para compreensão da atualidade brasileira. Ao pensarmos em uma prática verdadeiramente emancipatória, não podemos nos furtar de tratar deste assunto, já que para se alcançar a efetividade do acesso à justiça, é necessário antes admitirmos certos privilégios e preconceitos advindos desde os tempos coloniais, para então conseguirmos superá-los. O intuito deste artigo é justamente trabalhar com essas questões, buscando analisar e encontrar caminhos possíveis que quebrem com os paradigmas dominantes e façam surgir os paradigmas emergentes, fortalecidos pela análise e discussão histórica.

Palavras-Chaves: Descolonização; Emancipação; Acesso à Justiça; Desigualdades; Práxis.

\section{DECOLONIZATION AND ACCESS TO JUSTICE: PERSPECTIVES FOR AN EMANCIPATORY PRACTICE}

\begin{abstract}
: the decolonization process is of utmost importance for understanding the brazilian reality. When we think of a truly emancipatory practice, we can not avoid to treat on this subject, since to achieve the effectiveness of access to justice, it is necessary before we grant certain privileges and prejudices arising from colonial times, and then we can overcome them. The purpose of this article is just working with these issues, trying to analyze and find possible ways to break with the dominant paradigms and do arise emerging paradigms, strengthened by historical analysis and discussion.
\end{abstract}

Keywords: Decolonization; Emancipation; Access to Justice; Inequalities; Praxis.

\section{INTRODUÇÃO}

A história do Brasil demonstra uma vontade quase que incessante de manutenção de estruturas e continuidade de paradigmas, por mais que estes acentuem preconceitos e cause

\footnotetext{
${ }^{1}$ Mestre em Filosofia do Direito e Teoria do Estado pela Pontifícia Universidade Católica de São Paulo (2017). Bacharel em Direito pela Universidade Nove de Julho (2014). Licenciado em História pelas Faculdades Integradas de Guarulhos (2009). Membro do grupo de pesquisas "Epistemologia Política do Direito". Endereço eletrônico: o-viegaz@uol.com.br. Orcid: https://orcid.org/0000-0002-9657-2200.

${ }^{2}$ Mestrando em Direito pela Universidade Nove de Julho (UNINOVE). Pós-Graduado em Direito e Processo do Trabalho pela Faculdade de Direito Professor Damásio de Jesus (2016). Pós-Graduando em Direito e Processo Civil pela Escola Superior de Advocacia (ESA). Bacharel em Direito pela Universidade Nove de Julho (2014). Endereço eletrônico: arari vinicius@yahoo.com. Orcid: https://orcid.org/0000-0003-0376-5271.
}

Revista Brasileira de História do Direito| e-ISSN: 2526-009X| Porto Alegre | v. 4 | n. 2 | 
diferenças na sociedade, problemas que vão além de questões puramente raciais, estando também nos meandros da economia, da política e do direito.

Apontar desigualdades é simples, o difícil é encontrar caminhos válidos para construção de uma saída ou de possibilidades para se reverter a situação é tarefa árdua para muitos, já que significa ter um olhar antropológico sobre o assunto e, por vezes, se despir dos próprios privilégios já existentes e contínuos antes mesmo do nascimento.

Com este esboço procuramos dar continuidade aos estudos da desigualdade e de como ela afeta a efetivação do acesso à justiça na práxis. Não procuramos simplesmente apontar defeitos, como também identificar formas possíveis de se alcançar a emancipação a partir de um novo paradigma emergente.

Para tanto, a investigação do processo de descolonização ao qual o Brasil ainda passa ganha contornos interessantes, uma vez que muitos dos institutos jurídicos, sociais, políticos e econômicos praticados ainda hoje têm sua gênese na má-transição realizada com a independência e a não-construção de um efetivo paradigma desprendido das ideias colonizadoras portuguesas.

Para se pensar numa solução para os problemas atuais do acesso à justiça não podemos deixar de passar por esta fase transitória e analisarmos a sua situação na contemporaneidade. Caso contrário, estaríamos pulando etapas do processo de construção histórica, preponderante para compreensão do presente.

Neste pequeno texto, procuramos nos valer dessas premissas para construir uma base sólida para verificarmos a incidência das desigualdades no acesso à justiça (e à informação sobre os direitos) como manifestação do paradigma dominante que não permite surgir a emancipação necessária.

Para tanto, apresentamos um trabalho que perscruta a análise de um Brasil contemporâneo em que o acesso à justiça, apesar de instado no texto constitucional, não é alcançado, mostrando-se que o verdadeiro objetivo deste breve esboço é levar à discussão e ao pensamento crítico sobre os caminhos que estamos buscando para alcançarmos essa possibilidade, através de uma análise que se permeia, sobretudo, pelos estudos de contextualização histórica, social, jurídica e filosófica prementes para nossos objetivos.

\section{Desigualdades e o Paradigma Dominante}


As influências das desigualdades naturais e políticas na formação e constituição da sociedade permeiam com base no pensamento de Jean-Jacques Rousseau e suas contribuições para compreender como essas desigualdades existem e se apresentam de forma determinante na vida em comum.

Nos propomos neste segundo texto sobre o acesso à justiça a não nos esquecermos os ensinamentos rousseaunianos, mas procurar levar em apreço e sob outra perspectiva abordar a desigualdade que se vislumbra como herança histórica colonial e que, mesmo com a descolonização portuguesa, não somente persiste, como também movimenta as máquinas burocráticas estatais e dificultam a necessária efetividade dos direitos estabelecidos pela Constituição Federal.

A característica comum das Américas foi a colonização europeia que se constituiu como fator determinante de exploração após o advento das Grandes Navegações iniciadas durante o Século XV e continuadas pelo estabelecimento do domínio colonial. A base desse sistema se concentrava no chamado Capitalismo Mercantil, em que as colônias passam a ser vistas com vieses puramente econômicos, provedoras da extração de produtos escassos no continente europeu e que sustentavam a economia extrativista dessas civilizações.

Contudo, mais do que o caráter puramente econômico marcado pela extração de riquezas, existia um intuito fortemente presente de subjugação dos povos colonizados, traduzido não apenas pela exploração da mão de obra escrava (no caso brasileiro, primeiro com os indígenas e posteriormente com os negros africanos), mas também com a imposição de todo um aparato cultural estranho a esses povos.

Na sua globalidade, a compreensão, quer da cultura brasileira, quer do próprio Direito, não foi produto da evolução linear e gradual de uma experiência comunitária, como ocorreu com a legislação de outros povos mais antigos. $\mathrm{Na}$ verdade, o processo colonizador, que representava o projeto da Metrópole, instala e impõe numa região habitada por populações indígenas toda uma tradição cultural alienígena e todo um sistema de legalidade "avançada" sob o ponto de vista do controle repressor e da efetividade formal. (WOLKMER, 2014, p. 49).

É do senso comum imaginar que a subjugação colonial se baseou na economia e na utilização de escravos. Tal concepção é simplória e não abarca a totalidade de acontecimentos, haja vista que para se alcançar a efetividade almejada seria necessário mais do usurpar-lhes seu trabalho e o fruto dele, mas controlar igualmente sua liberdade e ter poder sobre a vida de todos 
os cidadãos, incluindo com isso a completa aniquilação de quaisquer arquétipos que porventura guardassem referência com suas antigas crenças, culturas e povos.

Essa característica predominante se deve à herança romanística, já que os romanos utilizavam-se da força para se fixar nos territórios conquistados, incluindo-se neste aspecto a destruição das antigas bases desses povos. A abdicação impositiva pode ser vista, por exemplo, por meio da evangelização indígena e negra, que deveriam negar suas religiões originais e se converterem ao deus cristão.

Diante do domínio e predomínio da cultura cristão-europeia, os colonizados foram inseridos nesta realidade que lhes era alheias aos seus antigos acontecimentos diários. De igual forma, os colonos portugueses que aqui se estabeleceram estavam sob a égide de estruturas que não lhes serviam, mas tinham somente como objetivo os interesses da Coroa e daqueles que dominavam a política econômica.

A ideia do paradigma dominante surge com a racionalidade do período renascentista, em que as ciências começam a se apoiar na busca incessante pelo conhecimento seguindo regras metodológicas e princípios epistemológicos. Qualquer outra forma que tentasse se constituir fora dessas linhas deveria ser desconsiderada.

Sendo um modelo global, a nova racionalidade científica é também um modelo totalitário, na medida em que nega o caráter racional a todas as formas de conhecimento que se não pautarem pelos seus princípios epistemológicos e pelas suas regras metodológicas. É esta a sua característica fundamental e a que melhor simboliza a ruptura do novo paradigma científico com os que o precedem. (SANTOS, 2000, p.61).

Esse rompimento realizado com o racionalismo durante a Renascença influiu diretamente nos rumos das ciências gerais, inclusive sobre os meandros da sociedade e como essa exclusão por qualquer outra forma não instituída nos parâmetros ocidentais (leia-se europeus) auxiliou para formar e fortalecer o paradigma dominante que estratificou o Estado, as desigualdades e a exclusão, tornando-se algo institucionalizado na realidade nacional.

Transpondo para um tipo ideal de racionalidade, além de quebrar com as ideias antes concebidas, passa a trazer também como as políticas estatais regulariam a vida em sociedade, de modo a impedir a manifestação de todos os agentes que fazem parte dela, deixando o real controle apenas com alguns grupos hegemônicos que teriam todo o aparato do Estado para usar naquilo que de útil tivesse aos seus interesses. 
Este modelo de burocratização das relações estatais (e até mesmo entre particulares) permaneceu e se consolidou como parte fundante dos paradigmas dominantes de desigualdades que se propagaram no Brasil como modelos perfeitos de política social, acentuando as diferenças e atingindo toda a sociedade ao excluir dos centros de poder parcelas significativas da população em geral.

Se as desigualdades políticas em Rousseau, criadas pelos homens e confirmadas pelas leis, formaram todo um aparato hierarquizado de sustentação que separou as classes existentes na sociedade, podemos verificar pela ideia geral do capitalismo ocidental que as desigualdades criaram um eficaz sistema de exclusão-inclusiva, em que ao mesmo tempo retira (exclusão) e insere (desigualdade) os cidadãos da vida cotidiana.

\begin{abstract}
A desigualdade e a exclusão são dois sistemas de pertença hierarquizada. No sistema de desigualdade, a pertença dá-se pela integração subordinada enquanto que no sistema de exclusão a pertença dá-se pela exclusão. A desigualdade implica um sistema hierárquico de integração social. Quem está em baixo está dentro e a sua presença é indispensável. Ao contrário, a exclusão assenta num sistema igualmente hierárquico mas dominado pelo princípio da segregação: pertence-se pela forma como se é excluído. Quem está em baixo, está fora. (SANTOS, 2008, p. 280).
\end{abstract}

Atentemo-nos ao que nos parece a institucionalização do paradigma dominante resultante do processo colonial estabelecido pelos europeus em suas terras conquistadas, criando um domínio sócio-espacial preponderante para o sucesso do empreendimento central (extração de riquezas), mas funcionando igualmente bem em outros setores da sociedade (trabalho escravo, estruturação burocrática política e jurídica ou a segregação nas várias camadas sociais).

A prática desses dois paradigmas possibilitou a formação de modelos que se espalharam de maneira substancial no país. O resultado de anos de exploração lastreados pela desigualdade e exclusão foram construídos socialmente e fortificados pela presença de políticas públicas que não acomodam os interesses comuns da Nação, mas respeita e se direciona a determinados grupos e interesses privalísticos.

A exclusão-inclusiva, clara manifestação do estado de exceção das democracias modernas, é o principal meio de assentar a continuidade de privilégios há muito existentes ao passo que fomenta a necessária inserção desse paradigma dominante como uma das muitas dificuldades de se pensar numa possibilidade de emancipação. 
Para que isso ocorra de maneira eficaz, não se pode deixar que seja aparente ou pelo menos não se pode deixar margens para que assim se pense, isto é, na atualidade não há como exercer o mesmo tipo de controle extremo dos tempos coloniais ou imperiais, ou caso contrário a percepção da vigilância extremada seria facilmente compreendida por aqueles em que o domínio é exercido.

A regulação social da modernidade capitalista se, por um lado, é constituída por processo que geram desigualdade e exclusão, por outro, estabelece mecanismos que permitem controlar ou manter dentro de certos limites esses processos. Mecanismos que, pelo menos, impedem que se caia com demasiada frequência na desigualdade extrema ou na exclusão/segregação extrema. Estes mecanismos visam uma gestão controlada do sistema de desigualdade e de exclusão, e, com isso, a redução das possibilidades de emancipação social às que são possíveis na vigência do capitalismo. (SANTOS, 2008, p. 282).

Tal controle, não podendo ser extremado para passar despercebido, se apresenta principalmente sob a ótica do psicológico, exercendo influência fundamental nos modos de agir e pensar da sociedade, de modo que o Estado e os agentes que o dominam possam ditar os rumos de tudo sem os incômodos de rebeliões ou revoluções por parte das camadas mais desiguais e exclusas da sociedade cívica.

A Biopolítica de Foucault explica esse fenômeno ao considerar o controle sobre os corpos por meio da sexualidade, bem como pelo exercício mental de deixar a todos cientes da vigilância constante exercida pelo Estado e que cumprem fielmente a sua função de impedir que as desigualdades e exclusões sejam extremas e evidentes, propiciando a falsa verdade de que todos possuem direitos e todos são iguais no exercício desses fundamentos legais.

Dentre as formas de se garantir a plena manutenção desses paradigmas está a falaciosa ideia liberal de se conceder direitos igualitários para todos e inseri-los na realidade como se dela fizessem parte, quando se é sabido que as desigualdades e a exclusão são os fundamentos da continuidade do regime.

A constatação dos impactos causados nas estruturas brasileiras é perceptível devido a outro ponto que nos permite a análise: a descolonização, processo pelo qual todas as ex-colônias europeias passaram desde o início do Século XIX até meandros da década de 1970, reflexos que ainda hoje se manifestam e por isso merecem algumas considerações a respeito.

\section{Descolonização e Descolonizados: DecorrênCias Paradigmáticas}


Como vimos, o Brasil foi um país colonizado, ação essa que se iniciou na economia e reverberou em todos os outros pontos da sociedade, desde o aparato jurídico-político da formação estatal até as mudanças drásticas no ideário cultural-religioso, inclusive com a morte e o assassinato de índios e negros que se recusavam a seguir as imposições lusitanas.

O estabelecimento de um ou mesmo vários paradigmas dominantes é reconhecidamente um dos fatores essenciais do processo de colonização de um povo. Na verdade, podemos afirmar que as imposições do colonizador sobre os colonizados é de maneira tão violenta e incisiva que nos parece uma prova de fogo, na qual aqueles que passarem por todas as pesadas exigências vivem (ou sobrevivem).

As decorrências paradigmáticas desse modelo são observadas na história, em que as desigualdades e a exclusão, típicos do período colonial, permanecem como fundamentos primeiros das relações sociais, econômicas, políticas, jurídicas ou educacionais do país, ainda que existente a famosa mas não eficiente igualdade legal.

Os processos de descolonização, segundo o Professor Boaventura de Sousa Santos, devem ser entendidos em dois momentos distintos, ambos posteriores à independência do colonizador e decorrentes das análises oriundas das formas coercivas outrora estabelecidas e como essas práticas reverberam na sociedade, além do principal ponto de desconstruir as ideias que não se coadunam com a realidade e os anseios daquela dada ex-colônia.

O pós-colonialismo deve ser entendido em duas acepções principais. A primeira é a de um período histórico, o que se sucede à independência das colónias. A segunda é de um conjunto de práticas (predominantemente performativas) e de discursos que desconstroem a narrativa colonial, escrita pelo colonizador, e procuram substituí-la por narrativas escritas do ponto de vista do colonizado. (SANTOS, 2008, p. 233).

Esse trabalho não é simples. Afinal de contas, é necessária a análise histórica do período colonial já estando sob a vivência do pós-colonialismo. Em segundo plano, a práxis se torna um grande problema, pois não se trata de algo analítico como o proposto da análise colonial, mas sim de uma verdadeira ação diária para se desconstruir as heranças negativas deixadas pelo colonizador.

Procura-se a desconstrução das estruturas colonizadoras para criação e fortalecimento de estruturas próprias dos antigos colonizados, pautados de acordo com seu ponto de vista, isto é, a prática decorrente da análise histórica do primeiro momento e da desconstrução deste segundo. 
Tomando por base o caso brasileiro, percebemos de imediato a dificuldade de desconstrução dos antigos paradigmas dominantes implantados ao longo da Colônia e de outros que foram inseridos ao longo da história, mesmo após a independência (lembremos que, durante o Império, os grandes fazendeiros enviavam seus filhos para tomar suas letras no curso de Direito da Universidade de Coimbra para aprender sobre a burocracia portuguesa e posteriormente aplicá-la ao Brasil $\left.^{3}\right)$.

É complicado pensarmos na transição paradigmática, uma vez que o entrechoque secular já está mais do que estabelecido, como igualmente arraigado no inconsciente coletivo da civilização. Não é possível puxar e arrancar de uma só vez e colocar em práticas novas técnicas e metodologias sem que se tenha uma real modificação no pensamento geral sobre o assunto.

Em certos aspectos, com o tempo, as práticas identitárias de colonizador e colonizados passam a se tornar indistintas, principalmente com a independência e o pós-colonialismo, de modo que fica ainda mais difícil e complexo separar o joio do trigo e estabelecer novas práticas com vistas ao fortalecimento da identidade do antes colonizado, que sempre foi inferiorizado.

\begin{abstract}
A identidade pós-colonial, ao romper com a distinção clara entre identidade do colonizador e a identidade do colonizado, tem de ser construída para o centro hegemónico, a partir das margens das representações e através de um movimento que vai dar margens para o centro. É este o espaço privilegiado da cultura e do crítico pós-colonial, um espaço-entre, liminar. (SANTOS, 2008, p. 236).
\end{abstract}

Trata-se de uma passagem, na qual o centro é um espaço-entre, um lugar vazio tendo em vista a descolonização e a ausência de um colonizador para ocupá-lo. A região periférica, antes espaço-próprio das instituições dos colonizados, outrora marginalizadas e ignoradas em detrimento de outros interesses estranhos a sua realidade. Na passagem de um para o outro, por evidência que a homogeneidade cultural ainda será perceptível ${ }^{4}$, mas as fronteiras antes intransponíveis quando do pensamento colonizador se tornam concretas e passiveis de transformação.

\footnotetext{
${ }^{3}$ Sobre o tema, ver a já citada obra de Antônio Carlos Wolkmer.

${ }^{4}$ Neste sentido, complementa o Professor Boaventura de Sousa Santos: "Trata-se de um espaço de fronteira, de extremidade ou de linha da frente onde só é possível a experiência da proximidade da diferença. É neste espaço que é construída e negociada a diferença cultural. A diferença cultural subverte as ideias de homogeneidade e uniformidade culturais na medida em que se afirma através de práticas enunciativas que são vorazes em relação aos diferentes universos culturais que se servem". (SANTOS, 2008, pp. 236-7).
} 
Evidencia-se, neste espectro, um forte pluralismo conjectural que ocorre num mesmo espaço, entre ideias e pontos de vistas dos colonizados e dos colonizadores. No orbe jurídico, por exemplo, as relações acontecem no mesmo espaço e não necessariamente são conflituosas, por vezes havendo até integração, como normas sociais que dialogam com normas jurídicas sem problemas de conflitos.

O colonialismo jurídico português é um dos muitos paradigmas que permearam a sociedade por conta do choque entre colonizador e colonizado. Se ele pode ocorrer de maneira não-conflituosa, no caso brasileiro temos o oposto disso, havendo uma contraposição de culturas e sua supressão não acontece de uma única vez pelo uso da força, não se podendo sufocar totalmente a antiga cultura de imediato. É isso que permite, mais tarde, que se desconstrua os antigos paradigmas para a efetivação de novos conceitos estruturais.

Esse caminho, contudo, também não é simples. Da mesma forma que existem problemas do colonizador em acabar com os paradigmas dos colonizados quando da descoberta, os colonizados encontrarão também dificuldades para se livrar das heranças dos colonizadores quando da independência e construir seus próprios ideários, até mesmo porque "só muitos anos, senão mesmo séculos, depois da morte de um paradigma sócio-cultural, é possível afirmar com segurança que morreu e determinar a data, sempre aproximada, da sua morte" (SANTOS, 2000, p. 15), tendo claro que a vida de um conceito estrutural arraigado no âmago de uma dada sociedade supera e muito a vida de um ser humano, motivo mais do que suficiente para compreendermos a difícil tarefa de se construir um paradigma próprio.

Trata-se de uma passagem fúnebre, na qual a morte de um paradigma somente poderá ser determinada não no exato instante em que ocorre a independência ou o início da descolonização, mas sim quando estiver completamente destruído pelo novo conhecimento, pensamento sustentado pelo senso crítico dos antigos colonizados, que agora procuram no antigo espaço do colonizador o local ideal para afluência de suas ideias e perspectivas jurídicas, mesmo diante das muitas dificuldades encontradas para suplantar o pensamento jurídico e o conhecimento científico dos antigos colonizadores.

O colonial constitui o grau zero a partir do qual são construídas as modernas concepções de conhecimento e direito. As teorias do contrato social dos séculos XVII e XVIII são tão importantes pelo que dizem como pelo que silenciam. O que dizem é que os indivíduos modernos, ou seja, os homens metropolitanos, entram no contrato social abandonando o estado de natureza para formarem a sociedade civil. O que silenciam é que, desta forma, se cria uma vasta região do mundo em estado de natureza, um estado de natureza a que são condenados milhões de seres humanos sem quaisquer possibilidades 
de escaparem por via da criação de uma sociedade civil. (SANTOS, 2007, pp. $3-46)$.

Para os colonizados será sempre difícil superar o paradigma dominante, principalmente quando toda a estrutura da sociedade está baseada nas heranças deixadas pelo colonizador, denotando que, apesar de não mais controlar diretamente os meandros daquela civilização, permanecem vivos na mente humana por séculos em práticas que não se coadunam com a realidade social daquela localidade.

As ideias liberais e o contratualismo no Brasil foram adaptados para servirem aos interesses de quem detinha o poder, numa clara manifestação de controle e manutenção do status quo. Essa prática decorrente dos "jeitinhos" dados e inventados durante o período colonial permanece vívida na atualidade, trazendo consigo a falsa ideia de igualdade legal atribuída a todos os cidadãos, além de silenciar, com isso, aqueles que estão à margem e excluídos dos reais processos civis e políticos.

A latente dificuldade de se encontrar os meios necessários para superar a desigualdade e a exclusão são decorrentes das próprias práticas iniciadas pelos colonizadores e continuadas pelo colonizados, apenas elegendo-se um novo foco: se antes destinava-se dos colonizadores a todos os colonizados, passa-se a separar aqueles que da sociedade detém algum poder econômico-político àqueles que nada possuem. Segundo Boaventura de Sousa Santos, “a definição da transição paradigmática implica a definição das lutas paradigmáticas, ou seja, das lutas que visam aprofundar a crise do paradigma dominante e acelerar a transição para o paradigma ou paradigmas emergentes" (SANTOS, 2000, p. 19). É um árduo trabalho que precisa ser feito.

A luta constante é encontrada de igual forma nos contrastes que surgem entre as muitas ideias que procuram ser paradigmas emergentes contra as ideias do paradigma dominante já constituído. A clareza dessa afirmação pode ser percebida quando analisamos o Brasil Império, já em proximidade da Proclamação da República, havendo embates significativos de ambos os lados.

É nas duas décadas anteriores à proclamação da República que mais claramente sobem à tona numerosas contradições íntimas do sistema político do império: contradição entre o princípio moderno da soberania popular e o da sanção divina; entre um sistema nominalmente representativo e a carência de verdadeira representação; entre um regime de natureza aristocrática e a inexistência de aristocracias tradicionais; entre um liberalismo formal e a falta de autêntica democracia; finalmente entre uma carta outorgada, de cunho 
acentuadamente monárquico, e uma Constituição não escrita que pende para o parlamentarismo. (HOLANDA, 2012, pp. 22-3).

Ressalte-se que, conforme já afirmamos, não necessariamente os paradigmas entrarão em conflitos, sendo que por vezes coexistem numa mesma realidade. É o que podemos perceber nas relações acima descritas, em que o choque ocorria, mas os conflitos não e, mais do que simplesmente coexistirem, eles equilibravam-se entre $\mathrm{si}^{5}$, por mais contraditório que possa ser.

Evidentemente, não se trata de afirmar que por ser um conflito entre um paradigma emergente contra um dominante que o emergente estará sempre de acordo com a realidade fática (até mesmo porque é assim que o dominante se estabelece e se fortalece), mas sim que depois de um século, aquilo que era emergente se tornou dominante e impacta diretamente nos rumos da sociedade.

Paradigmas dominantes e paradigmas emergentes encontram-se em luta no Brasil há alguns séculos, não sendo nenhuma novidade. O problema, na realidade, é a falta de profundidade dos novos paradigmas emergentes, tanto que ainda na atualidade muitas dessas questões não estão ou foram muito mal resolvidas, deixando arestas gigantes e prejudiciais num pensamento brasileiro.

Tanto é verdade que a busca pela efetividade de determinados direitos que, apesar de constarem nos textos legais e, principalmente, nos textos constitucionais, jamais foram realmente destinados à sociedade, mas sim à pessoas e grupos seletos que dominam todas as instâncias sociais e influem significativamente nos centros decisórios do Estado, tomando para si os únicos "merecedores" dos consagrados direitos.

O senso crítico é necessário, ou continuaremos a fingir que basta a existência e inserção de determinado direito no texto legal para que tudo se resolva, fechando os olhos para a efetividade que se busca ao se tratar de garantias fundamentais dos cidadãos, o que ocorre com o acesso à justiça pela ausência de verdadeiras políticas que procurem não apenas identificar os problemas, mas que apresentem por seu turno mudanças e soluções práticas.

\section{EMANCIPAÇão E ACESSo À JUSTiÇA}

\footnotetext{
${ }^{5}$ Neste sentido: “A presença de alguns desses contrastes não constituiria uma novidade, pois não faltam na história das nações modernas exemplos de como eles podem por algum tempo coabitar; a novidade está em terem conseguido equilibrar-se tão longamente, quase três quartos de século, e em tamanha profusão, em terra onde tudo parece conspirar, desde o começo, contra sua sobrevivência". (HOLANDA, 2012, pp. 22-3).
} 
Analisando toda a discussão acerca das possibilidades e tendências existentes nas relações que permeiam a sociedade brasileira, verificamos a enorme dificuldade em encontrarmos modelos paradigmáticos que levem às políticas emancipatórias capazes de modificar a atualidade.

Quando pensamos em desigualdades e no processo de descolonização, percebemos o quanto estes dois aspectos são ainda muito presentes ao mesmo tempo em que a discussão sobre sua existência e alcance não encontram respaldo na maior parte dos meios propícios para este tipo de debate. Pelo contrário, esses centros servem para proliferar paradigmas dominantes que impedem a emancipação de surgir e se manifestar em sua plenitude, acarretando em graves consequências ao modelo institucional brasileiro, que permanece em sua estrutura rígida de pouca ou nenhuma modificação.

Se considerarmos por este ponto, veremos que as políticas que buscam a emancipação, na verdade, nada mais são do que políticas regulatórias, que não somente atestam aquilo que já existe, como também sufocam o surgimento das necessárias mudanças que poderiam transformar a regulação em emancipação.

Embora tenhamos consciência da dificuldade de se iniciar e levar o progresso da superação paradigmática, são os paradigmas regulatórios dominantes que deixam no limbo determinadas práticas que mexeriam nas estruturas e permitiriam o surgimento de outras formas de atuação do Estado, da sociedade e dos cidadãos, quebrando-se com o fantasma da continuidade de formas que, apesar de não mais oficialmente existentes, permanecem impregnadas na cultura como algo natural.

A transição paradigmática é, assim, um ambiente de incerteza, de complexidade e de caos que se repercute nas estruturas e nas práticas sociais, nas instituições e nas ideologias, nas representações sociais e nas inteligibilidades, na vida vivida e na personalidade. E repercute-se muito particularmente, tanto nos dispositivos da regulação social, como nos dispositivos da emancipação social. Daí que, uma vez transposto dos umbrais da transição paradigmática, seja necessário reconstruir teoricamente uns e outros. (SANTOS, 2000, p. 257).

Ao se levar em consideração as formas com que o processo de descolonização se realizou no Brasil, por certo encontraremos as causas atuais de muitos dos problemas para efetivação de determinados direitos que, presos às estruturas jurídicas e pensamentos culturais antigos, não conseguem encontrar o campo necessário para a formação de um paradigma 
emergente real, isto é, o processo de descolonização brasileiro passou pelo primeiro estágio de independência, mas não conseguiu se firmar na segunda parte deste processo para se quebrar com os paradigmas dominantes.

Explica-se, porém, por alguns aspectos da própria estrutura formada no pósindependência, principalmente: (i) apesar de quebrar os laços com a Metrópole, o Brasil passou a ser governado pelo Imperador Pedro I que, dentre outros, era herdeiro do trono português; (ii) as velhas e arcaicas composições agrárias não perderam suas forças e ainda viram sua importância crescer consideravelmente, garantindo-se a manutenção do seu status quo; (iii) mesmo com todas as barreiras criadas ao liberalismo, os brasileiros conseguiram inseri-lo e mantê-lo convivendo por muito tempo com todas as estruturas contrárias a esta filosofia, como a escravidão e o modelo patriarcal; (iv) as discussões e debates políticos e ideológicos no país jamais se assentaram e se firmaram, ficando marcado sempre pela regulação e não pela emancipação.

Sérgio Buarque de Holanda, quando se propôs a encontrar as raízes do Brasil, chega a afirmar que a falta de determinadas estruturas no país se devia ao não surgimento de uma burguesia capaz de realizar o mesmo trabalho ideológico que se verificou na Inglaterra e na França, fortalecendo o próprio sentido da política emancipatória. O que se viu foram práticas voltadas para a regulação, de manter com os instrumentos próprios de cada período histórico as bases fixas de uma classe em detrimento das demais, não permitindo a real discussão dos problemas.

Tais implicações são decorrentes de um processo histórico não resolvido de aproximadamente duzentos anos e que continua reverberando. Ao pular etapas necessárias para a construção identitária nacional, o país impediu que as verdadeiras transformações que deveriam acontecer realmente ocorressem, transmutando ideias pertencentes ao paradigma dominante, mas colocados como fundamento ao paradigma emergente, que pouco se manifestou no Brasil.

Ganha destaque a relação já explicitada anteriormente sobre a desigualdade e a exclusão que, diferentemente do que ocorre nos países colonizadores, nas nações pós-coloniais se manifestam como verdadeiras formas de se regular a vida em sociedade, não tendo qualquer relação necessária com a emancipação esperada desses países, mas permanecendo como fundamento para justificar políticas públicas e os meios escolhidos pelo Estado para manutenção da "ordem". 
A desigualdade e a exclusão têm, pois, de ser justificadas como excepções legítimas ou incidentes de um processo societal que lhes não reconhece legitimidade, em princípio. E, perante elas, a única política social legítima é a que define os meios para minimizar uma e outra. Nada disso, como sabemos, vale para as sociedades sujeitas ao colonialismo europeu. Aí vigoraram a desigualdade e a exclusão como princípios de regulação cuja validade não implicou qualquer relação dialéctica com a emancipação. Durante o longo tempo do ciclo colonial, a "opção" para essas sociedade foi, quando muito, entre a violência da coerção e a violência da assimilação. (SANTOS, 2008, p. 279).

O caráter violento da dominação europeia se manifesta e reflete de igual maneira nas formas com que regulação se reveste de emancipação e se espalham como prática socialmente aceita para este fim, o que certamente não condiz com a verdadeira função dialética da regulação-emancipação, embora se encaixe perfeitamente nos desígnios daqueles que dominam o Estado e as formas de manifestações da política, seja ela neste caso regulatória ou emancipatória.

O exemplo primordial dessa má-formação é a apropriação da ideia de igualdade legal, própria do liberalismo, e sua inserção numa realidade que em nada refletia a possibilidade de se haver uma mudança significativa para se diminuir a desigualdade reinante. Isto ocorre porque as tentativas no país visando mudanças jamais passaram do plano legal, não se buscando em contrapartida a efetividade. Na realidade, vemos este problema inclusive com grupos sociais, que lutam diariamente por direitos e quando finalmente alcançam a sua forma legal, param as lutas e se calam, demonstrando que o intuito não era necessariamente a emancipação (que aqui colocaremos como efetividade), mas sim a simples regulação (confirmação da existência dos seus direitos).

Pode não ser a realidade em todos os meios da sociedade. Contudo, não podemos ignorar que é a maneira na qual se encontram boa parte das instituições cívicas e a forma com que a maioria esmagadora dos brasileiros pensam. As conquistas não estão no campo da práxis diária e sim apenas na positivação e no reconhecimento por parte de Estado de direitos que se perdem nas letras da lei e que por vezes não encontram respaldo nem mesmo nos grupos que lutavam por eles.

Este é o panorama quando analisamos a efetividade do acesso à justiça, em que as políticas regulatórias se transformam em modelos emancipatórios que em nada auxiliam ou contribuem para a real emancipação, auxiliando, de outra via, a continuidade do paradigma dominante. A melhor forma de observarmos como as relações do Estado e a efetividade do 
acesso à justiça se fazem no plano prático é, segundo Boaventura de Sousa Santos, pela análise do processo civil, devido a sua forma e características próprias em que se é possível verificar a verdadeira busca pela justiça.

O tema do acesso à justiça é aquele que mais directamente equaciona as relações entre o processo civil e a justiça social, entre igualdade jurídicoformal e desigualdade sócio-económica. No âmbito da justiça civil, muito mais propriamente do que no da justiça penal, pode falar-se de procura, real ou potencial, da justiça. Uma vez definidas as suas características internas e medido o seu âmbito em termos quantitativos, é possível compará-la com a oferta da justiça produzida pelo Estado. (SANTOS, 2010, p. 167).

É um movimento interessante a observação do sociólogo português, não por excluir as demais formas de acesso à justiça, mas sim por observar características que permitem colocála mais facilmente sob a análise dos seus impactos jurídicos e sociais. Sobre a justiça penal, por exemplo, afirma na mesma obra que é uma procura forçada de justiça por parte do réu (embora em termos globais fale-se igualmente de procura da justiça penal).

A base dessa constatação está além dos argumentos jurídicos. Encontra respaldo principalmente nas questões socioeconômicas, típicas do modelo capitalista que incentiva as relações econômicas como preponderantes na atual sociedade global pós-moderna, relações estas que permeiam todos os movimentos sociais e jurídicos das políticas estatais, posto que o Estado possui o papel de regulador das atividades da sociedade, incluindo, por óbvio, a prática de políticas não-emancipatórias.

Dentro deste modelo global e mercadológico, o que nos parece claro no processo de descolonização pelo qual o Brasil iniciou e ainda não terminou, os pobres e marginalizados são preteridos no acesso à justiça. As vantagens estão com os poderosos, os grandes grupos sociais e empresariais que dominam a política estatal e que podem ser chamados, segundo feliz definição de Milton Santos, de agentes hegemônicos, que se encontram em todas as instâncias do Estado.

Um exame dessas barreiras ao acesso, como se vê, revelou um padrão: os obstáculos criados por nossos sistemas jurídicos são mais pronunciados para as pequenas causas e para os autores individuais, especialmente os pobres; ao mesmo tempo, as vantagens pertencem de modo especial aos litigantes organizacionais, adeptos do uso do sistema judicial para obterem seus próprios interesses. (CAPPELLETTI; GARTH, 2002, p. 28).

A política de emancipação para efetivação do acesso à justiça não significa distribuir por toda a Constituição Federal e pela legislação infraconstitucional textos que guardam 
respeito com a justiça, sem que se tenha em contrapartida meios reais e concretos para que se realize o verdadeiro processo de inclusão e utilização dos mecanismos existentes.

O problema apontado pelo professor Mauro Cappelletti vai de encontro ao preceituado por Boaventura de Sousa Santos. Quando temos grandes figuras que dominam determinados setores do mercado e sua influência acaba inevitavelmente se alastrando ao Estado, tais organizações passam a se utilizar do sistema judicial para preservar seus próprios interesses, enquanto os sujeitos individuais da relação jurídica são preteridos em seus direitos, incluindo a efetividade do acesso à justiça.

Esta é uma manifestação clara do pensamento abissal, em que de um lado da linha (norte) está o imperialismo, tanto colonial como neocolonial e do outro lado da linha (sul) encontram-se os povos colonizados, silenciados e oprimidos ao longo dos séculos de dominação. Se o que caracteriza esses dois extremos é a impossibilidade de copresença, vimos que o Brasil é um caso sui generis, em que durante anos e décadas ideologias contrastantes não apenas estiveram no mesmo ambiente como conviveram harmoniosamente e sem enfrentamentos.

Se levarmos em consideração que no Brasil não se passou o segundo estágio da descolonização, as influências dos agentes coloniais permanecem vivas na sociedade, transferidas neste momento para a hegemonia dos grupos e instituições que dominam a economia, isto é, não são necessariamente os colonos portugueses, mas exercem controle e poder de maneira tão forte e violenta quanto, interferindo diretamente no mercado, na política e nas relações sociais em geral, denotando que mais do que separar ricos e pobres do processo de acesso à justiça, separa-se por condicionantes ainda mais complexas do que as puramente econômicas.

A discriminação social no acesso à justiça é um fenómeno muito mais complexo do que à primeira vista pode parecer, já que, para além das condicionantes económicas, sempre mais óbvias, envolve condicionantes sociais e culturais resultantes de processos de socialização e de interiorização de valores dominantes muito difíceis de transformar. (SANTOS, 2010, P. 171).

Sobre o assunto, Darcy Ribeiro já nos havia alertado de que as desigualdades sociais no Brasil separam mais do que qualquer tipo de diferenças raciais ${ }^{6}$. Não estamos negando que

\footnotetext{
${ }^{6}$ Neste sentido: "Subjacente à uniformidade cultural brasileira, esconde-se uma profunda distância social, gerada pelo tipo de estratificação que o próprio processo de formação nacional produziu. $\mathrm{O}$ antagonismo classista que
}

Revista Brasileira de História do Direito | e-ISSN: 2526-009X| Porto Alegre | v. 4 | n. 2 | 
exista a segregação racial, mas sim que outros fatores incidem igualmente para criar o abismo entre as classes nacionais, atingindo na discriminação social com condicionantes sociais e culturais mais do que os fatores econômicos.

Não podemos esquecer, entretanto, que o processo de democratização do acesso à justiça não se faz ressaltando as desigualdades sabidamente existentes, muito menos reafirmando a necessidade de continuum processo de descolonização, que iniciamos e muito paulatinamente percorremos. É na práxis que está a nossa melhor chance de garantirmos que o acesso à justiça saia do texto legal e ganhe a sociedade.

Para isso, concordamos com a colocação do professor Boaventura de Sousa Santos, quando afirma que para se encontrar a democratização da administração da justiça, é necessária ter por dimensão que ela passará necessariamente pela democratização da vida social, econômica e política desta localidade. Para tanto, devemos observar dois pontos estruturantes do pensamento do sociólogo português para encaixarmos na nossa realidade, quais sejam:

(i) diz respeito à constituição interna do processo e inclui uma série de orientações, tais como: o maior envolvimento e participação dos cidadãos, individualmente ou em grupos organizados, na administração da justiça, a simplificação dos actos processuais e o incentivo à conciliação das partes; a ampliação dos conceitos de legitimidade das partes e do interesse de agir.

(ii) diz respeito à democratização do acesso à justiça. É necessário criar um Serviço Nacional de Justiça, um sistema de serviços jurídicos-sociais, gerido pelo Estado e pelas autarquias locais com a colaboração do acesso à justiça das partes das diferentes classes ou estratos sociais. (SANTOS, 2010, P. 177).

As duas formas citadas são fundamentais para se alcançar a verdadeira emancipação paradigmática e libertação do pensamento dominante existente na atualidade. O primeiro, correspondente à formação do próprio processo judicial, guarda relação com todos os atos e partes envolvidas para sua efetivação, referenciando-se sobretudo com o estabelecimento, controle e formas processuais. Sabemos que a celeridade, muito embora não a encontremos nas relações jurídicas e processuais brasileiras, deve estar relacionada a esta primeira vertente.

Sobre o segundo ponto, verifica-se a forte necessidade de criação de meios capazes para se garantir a efetividade. Mais do que uma associação ou o Conselho Nacional de Justiça, devemos esperar que a mentalidade da sociedade mude em muitos aspectos para que se tenha

corresponde a toda estratificação social aqui se exacerba, para opor uma estreitíssima camada privilegiada ao groso da população, fazendo as distâncias sociais mais intransponíveis que as diferenças raciais". (RIBEIRO, 2006, p. 20). 
realmente formas condizentes com a efetividade do acesso à justiça, para pobres e ricos, negros e brancos: todos cidadãos, sem rótulos.

Até mesmo porque o intuito desse tipo de instituição é eliminar todo e qualquer tipo de obstáculo para que se tenha a justiça, sejam esses obstáculos econômicos, sociais ou culturais ${ }^{7}$ e que de alguma forma impeçam o acesso de todos, garantido-se além do acesso à justiça, o acesso à informação sobre seus direitos.

Estas observações se devem principalmente ao fato de que as barreiras que se colocam para efetivação do acesso à justiça se inter-relacionam e isso deve ser considerado como importante fator quando da análise das necessárias políticas visando sua efetivação na sociedade, isto porque beneficiar ao extremo um lado, pode prejudicar ao extremo outro e, mesmo que na atualidade apenas os poderosos se beneficiem e prejudicam quem não tem acesso (desigualdade e exclusão), a total inversão desses valores criará igual desproporcionalidade, agora do outro lado.

Finalmente, como fator complicador dos esforços para atacar as barreiras ao acesso, deve-se enfatizar que esses obstáculos não podem simplesmente ser eliminados um por um. Muitos problemas de acesso são inter-relacionados, e as mudanças tendentes a melhorar o acesso por um lado podem exacerbar barreiras por outro. [...] Um estudo sério do acesso à Justiça não pode negligenciar o inter-relacionamento entre as barreiras existentes. (CAPPELLETTI; GARTH, 2002, p. 29).

Por óbvio, entendemos sim que devem haver políticas mais efetivas para se garantir aos menos favorecidos e instruídos o acesso aos meios capazes para se alcançar a justiça, o que não significa, todavia, que para isso deve-se negar os direitos já existentes, ou estaríamos criando uma outra maneira de desigualdade.

O que pretendemos dizer é que o aumento da efetividade do acesso à justiça deve acompanhar equitativamente a diminuição por parte dos agentes hegemônicos da quase completa exclusividade que a configuração atual do judiciário condiciona, permitindo-se com isso que ambas as partes possam ter condições de ingressar em um processo, demandar e se defender com os mesmos meios.

\footnotetext{
${ }^{7}$ Neste sentido: "Este serviço não se deve limitar a eliminar os obstáculos económicos ao consumo da justiça por parte dos grupos sociais de pequenos recursos. Deve tentar também eliminar os obstáculos sociais e culturais, esclarecendo os cidadãos sobre os seus direitos, sobretudo os de recente aquisição, através de consultas individuais e coletivas e através de acções educativas nos meios de comunicação, nos locais de trabalho, nas escolas, etc.". (SANTOS, 2010, p. 177).
} 
Pensar em políticas emancipatórias envolve um trabalho conjunto de história, sociologia e direito, para que se consiga quebrar com as barreiras do paradigma dominante colonial e se instaurar no curso do lento processo de descolonização meios capazes de se garantir a efetividade da justiça, do pensamento e das relações sociais como um todo, incutindo-se no brasileiro não apenas um ideal de real acesso à justiça, diferente do modelo de igualdade legal atual, como também e principalmente propiciar finalmente a verdadeira existência de um paradigma de emancipação nacional.

\section{CONSIDERAÇÕES FinaIS}

Colocamo-nos, pois, numa fase de transição paradigmática. O Brasil ainda passa por sua segunda etapa do pós-independência, o que justifica a presença de alguns paradigmas arcaicos do período colonial, mas não justifica, de outra via, a falta de discussões para sua superação.

A continuidade de muitos institutos que igualam no plano legal e desigualam no plano factual é um dos muitos resquícios que impedem a real efetivação do acesso à justiça por parte de todos e não apenas de parcelas seletas da sociedade, que ficam com todos os meios aprazes para satisfazer seus direitos.

Pensar a práxis emancipatória ao acesso à justiça sem passar e admitir as desigualdades seria falho, ignorando-se um dos maiores problemas para se garantir a efetivação de direitos consagrados há décadas apenas no papel e que não se realizam.

Devemos quebrar este paradigma dominante e pensar em um emergente capaz de assegurar a todos reais condições de alcançar a justiça, passando por todos os processos históricos necessários para tanto e chegando ao verdadeiro sentido da igualdade legal, qual seja, sua manifestação factual. Pensar o acesso à justiça é considerar como podemos alcançar novas formas de ver o Brasil, a sociedade e todas as formas de se desprender deste paradigma dominante que nos impede de seguir com um pensamento propriamente brasileiro.

\section{REFERÊNCIAS BIBLIOGRÁFICAS}

CAPPELlETTI, Mauro; GARTH, Bryant. Acesso à Justiça. Porto Alegre: Sérgio Antonio Fabris Editor, 2002. 
HOLANDA, Sérgio Buarque de. O Homem Cordial. São Paulo: Penguin Classics Companhia das Letras, 2012.

RIBEIRO, Darcy. O Povo Brasileiro: A Formação e o Sentido do Brasil. São Paulo: Editora Companhia das Letras, 2006.

SANTOS, Boaventura de Sousa. A Crítica da Razão Indolente - Contra o Desperdício da Experiência. São Paulo: Cortez Editora, 2000.

Para Além do Pensamento Abissal: Das Linhas Globais a Uma Ecologia de

Saberes. In: Revista Crítica de Ciências Sociais. Coimbra: Outubro 2007, no 78, pp. 3-46.

Disponível

em

$<$ http://www.ces.uc.pt/myces/UserFiles/livros/147_Para\%20alem\%20do\%20pensamento\%20 abissal_RCCS78.pdf>. Acesso em: 13/11/2015.

A Gramática do Tempo - Para Uma Nova Cultura Política. São Paulo: Cortez Editora, 2008.

Pela Mão de Alice - O Social e o Político na Pós-Modernidade. São Paulo: Cortez Editora, 2010.

WOLKMER, Antonio Carlos. História do Direito no Brasil. Rio de Janeiro: Editora GEN/Forense, 2014.

Revista Brasileira de História do Direito | e-ISSN: 2526-009X| Porto Alegre | v. 4 | n. 2 | 